\title{
Fri og villig: Kirkens SOS
}

\author{
Ved N ora Blaasvær
}

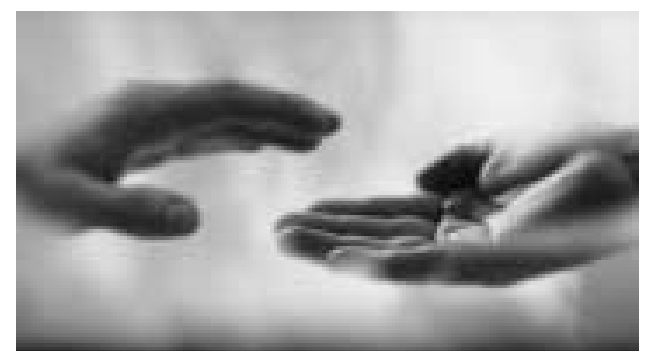

Det var midt i 70-åra. I Norge bygget vi velferdssamfunn med en stat som skulle dekke ethvert behov. Alt omsorgsarbeid skulle vaere profesjonelt arbeid. Midt i dette ble Kirkens SOS etablert. En krisetelefon som verken var verdinøytral eller profesjonell. Et tiltak hvor frivillig innsats var den baerende faktor, og hvor medmenneskelighet og personlig egnethet kvalifiserte til møter med mennesker i krise. Save Our Souls - dette kunne da umulig vaere god krisehåndtering?

Kirkens SOS er en døgnåpen krisetelefon som bemannes av 1200 frivillige medarbeidere. Døgnet rundt, hele året - det er alltid noen tilgjengelig for samtale på Kirkens SO S. Et lavterskeltilbud der du som inn ringer får være anonym, hvor samtalen er umiddelbar og uforpliktende. I 2000 besvarte KirkensSOS 110.000 henvendelser. Det sier noe om behovet for å ha et menneske å snakke med - og det sier mye om verdien av frivillig innsats.

Sommeren 1953 leste den anglikanske presten $C$ had Vara i avisen at London by hadde tre selvmord per dag. K ort tid etter satte han inn en annonse i Londonavisene: "Før du tar livet ditt - ring meg på M ansion H ouse $\mathbf{9 0 0 0 . " ~}$ Dette initiativet utviklet seg til The Samaritans i Storbritannia, og er den direkte forløper til K irkens SO S.

$C$ had Vara fikk nemlig ikke bare oppringninger fra selvmordstruede, men også fra mennesker som meldte seg til tjeneste. F rivillig innsats er basert på at noen ser at noe må gjøres - og gjør det.

\section{"Hvor mange trengs det?"}

"H vor mange trengs det? D et trengs én. Er det én som har vært der og sett, er det nok til å redde livet." (Skårderud 1998) Men for at Kirkens SOS alltid skal kunne tilby den ene som trengs, må vi ha et omfattende og stabilt nettverk av mennesker som er villige til å gi av sin tid, og som orker å forholde seg til nøden i andres liv. D et er alltid en utfordring å rekruttere nye medarbeidere til tjenesten. $0 \mathrm{~g}$ i en tid hvor frivilligheten er i endring (W ollebæk 2000), er dette et stadig tilbakevendende satsningsområde for Kirkens SOS.

Det er de 1200 frivillige medarbeiderne som danner ryggraden i virksomheten. $\mathrm{D} ø$ gnet rundt bemannes krisetelefonen av frivillige medarbeidere som uten godtgjørelse bruker av sin tid for å snakke med mennesker i krise. En krisetelefon skal være et godt og kvalitetssikret tilbud. Kirkens SO S har et omfatten de kvalitetssikringssystem som skal ivareta det møtet som finner sted mellom medarbeider og innringer, og som skal ivareta våre medarbeidere i deres tjeneste. Dette gjelder alt fra inntaksprosedyre til veiledning og vaktordning. Som medarbeider må man i snitt beregne å bruke tre kvelder/dager/ netter i måneden til tjeneste for Kirkens SOS. Vi er videre opptatte av at den enkel te medarbeiders innsats skal være forutsigbar. Det er derfor klare rammer rundt vaktordninger og medarbeiderskap ved Kirkens SOS. Vi definerer tydelig hvilke forventninger vi som organisasjon har til våre medarbeidere.

Som medarbeider må man gjennom en omfattende inntaksprosedyre, bestående av et søknadsskjema, en inntakssamtale på det aktuelle SO S-senter, samt et 40 timers innføringskurs for å forberede seg til tjenesten. I dette kurset inngår også prøvevakter med fadderordning. Kirkens SOS vektlegger den enkelte medarbeiders mulighet for å utvikle seg i tjenesten, og det er derfor jevnlig kunnskapsformidling i form av seminarer, kurs og foredrag. Det grundig kursing i sel vmordsproblematikk. M edarbeiderskapet formaliseres i en skriftlig kontrakt, hvor også oppsigel sesprosedyre er avtalt. V åre ordninger kan på mange måter sammenlignes med et arbeidsforhold, både hva gjelder grad av oppfølging og forpliktelser.

Virksomheten Kirkens SOS har utviklet sitt kvalitetssikringssystem gjennom en håndbok som beskriver hva vi gjør ved Kirkens SO S og hva vi ikke gjør. Det er for eksempel alltid minst to på vakt, det gjennomføres jevnlig og obligatorisk veiledning, og vi har klare rutiner for hva som er en medarbeiders handlingsrom.

En medarbeider har plikt til anonymitet på telefonen, man ringer aldri ut fra senteret, og man følger aldri opp en inn- ringer i ettertid. En medarbeider ved Kirkens SOS må kunne leve med uroen for hvordan det faktisk gikk med dette mennesket etter at man la på røret - det er en del av forutsetningen for vår tjeneste. Dette kan være vanskelig for en engasjert medarbeider, men alle forhold er lagt til rette for at medarbeiderne skal kunne jobbe med en slik uro i veiledning, samt i samtale med medvakt og/eller stab i løpet av vakten.

\section{Hvem ringer, og hvorfor?}

| 2000 besvarte Kirkens SOS 110.000 henvendelser. De to hovedtemaene vi i størst grad møter på tel efonen, er ensomhet og psykisk smerte. D et er flest kvinner som ringer oss (60\% er kvinner.) H ovedtyngden av dem som ringer oss, er i aldersgruppen 40 - 59 år. Vi har likevel sett en $ø$ kning i antall henvendel ser fra unge mennesker i de siste par årene. $\varnothing$ kningen i antall samtaler fra 1999 til 2000 har særlig vært i samtaler knyttet til selvmordsproblematikk. I 2000 var det 5.800 samtaler med selvmord som tema, og vi vurderte selvmordsrisikoen som alvorlig i 593 samtaler.

\section{Et selvmordsforebyggende tiltak}

I déen bak Kirkens SOS er at vi tilbyr et uforpliktende og umiddelbart møte med et menneske - her og nå. V i tilbyr ikke oppfølging, rådgivning eller annen hjelp utover văr tilstedeværelse og den følel sesmessige avlastning som ligger i den enkelte samtale. I en samtale kan medarbeider bidra med idéer og kunnskap som innringer kan ha nytte av i sitt liv, men det er til enhver tid innringers ansvar å omgjøre dem til praksis. Likevel har vi en kjøreregel ved Kirkens SOS som avviker fra det som er nevnt ovenfor. Vi sier tydelig at "Livet har forkjørsrett", og som et selvmordsforebyggende tiltak har vi til enhver tid beredskap for å ta i mot henvendelser fra mennesker som tenker på eller er i ferd med å ta sitt eget liv. 
Kirkens SO S vil i slike situasjoner gjøre hva vi kan for å hindre at dette skjer, og her griper vi faktisk og praktisk inn i innringers livssituasjon - så sant vi klarer å kartlegge hvor innringer befinner seg.

Kirkens SO S har et tett samarbeid med A kuttmedisin ske Kommunikasjonssentraler (A M K) i hele N orge, og dersom en medarbeider vurderer selvmordsrisikoen som alvorlig, kontaktes A M K med de opplysninger vi har fått om innringer. I 2000 ble denne rutinen fulgt i 289 samtaler. Vi forsøker å holde kontakten med innringer inntil A M K er på stedet. Dette er naturligvis noen av de mest dramatiske situasjoner en medarbeider opplever ved Kirkens SOS, og mye av vår kursing og tilrettel egging av tjenesten går på å ivareta dette på best mulig måte.

\section{Når starter et selvmord?}

Som et selvmordsforebyggen de tiltak tar KirkensSOS i mot akutte rop om hjelp, men vi er svært oppmerksomme på at den kontakten vi har med inn ringere som presenterer en mer permanent livssituasjon ( gjerne mennesker som ringer ofte), også betyr konkret og avgjørende livshjelp. For hvem kan si năr et selvmord starter? $\mathrm{H}$ vem kan vurdere verdien av det å ha et sted å ringe en eller flere ganger om dagen for å høre en stemme og få litt oppmerksomhet, i en hverdag preget av uforståelig ensomhet og stor psykisk smerte? Disse samtalene kan også være svært krevende for våre medarbeidere, da det kan oppleves mer belastende å ikke kunne gjøre noe, hjelpe til - enn faktisk å kunne gripe inn og gjøre noe konkret, slik man har anledning til, ved akutt sel vmordsfare.

\section{Et Kirkens SOS}

H ver vakt på Kirkens SO S innledes med en overlapping fra avtroppende vakt, samt en stund $i$ kapellet med bønn for vakten, virksomheten og dem som tar kontakt med oss. Det er mange av dem som ringer Kirkens SO S som ønsker forbønn, enten på telefonen eller ved at vi legger en lapp med deres anliggen de i bønneboka. Kirkens SOS tenner gjerne lys for dem som kontakter oss, og det er mange innringere som opplever det godt å vite at det nå står et lys et sted $\mathrm{i}$ landet og brenner for akkurat dem.

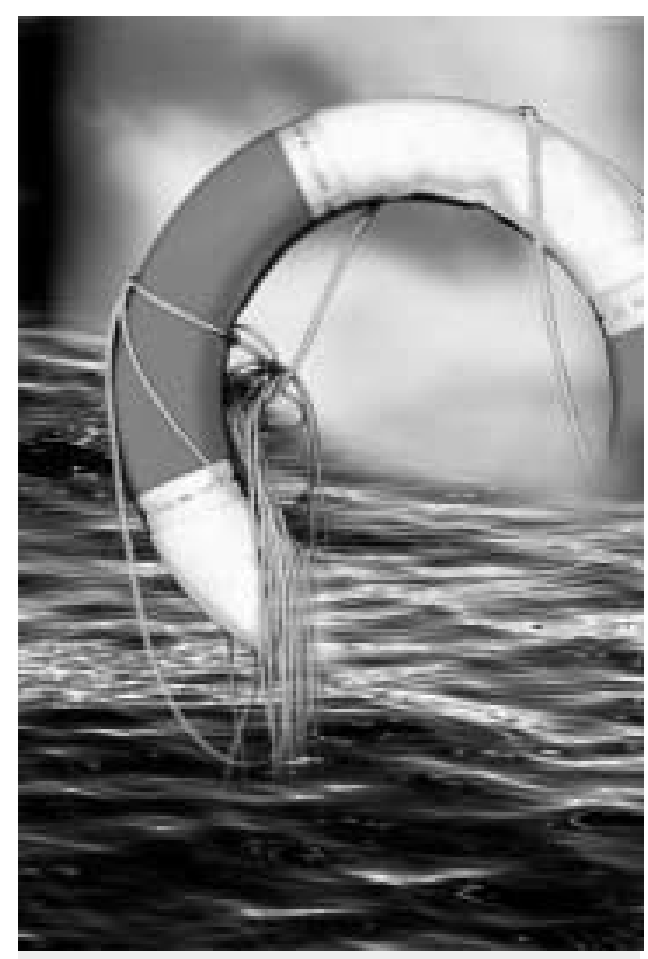

Frivillig ønske, håpe og tro

at guddommelig kjoerlighet

skinner mellom ordene, mellom tankene

\section{og gjennom tårene \\ $\mathrm{U}$ tdrag fra $\mathrm{H}$ ymne til den frivillige av Inger J. A as}

Er det så et hinder for tjenesten at den kalles for Kirkens SO S? Spørsmålet kommer ofte, og dette aspektet ved krisetelefonen har vært under stadig press. Vi kan selvfølgelig ikke se bort fra at enkelte som kunne trenge oss, vil ha gode grunner for ikke å henvende seg til noe kirkelig. Vi vet at mange mennesker er skadeskutte etter ublide og ukloke møter med kirke og med kristenliv. De vil naturlig nok vegre seg for å søke støtte fra den kanten. Det erkjenner Kirkens SOS, samtidig som vi utfordrer nøytral itetsbegrepet. I Kirkens SOS opplever vi at alle mennesker har farge, at ingen er nøytrale - og at vi blir sannere og tydel igere dersom vi er tydelige på vårt ståsted.

Vi opplever at å være et Kirkens SOS er et dilemma i den grad det hindrer noen $\mathrm{i}$ å ringe som kunne hatt nytte av det. Ellers opplever vi det som en ressurs.
Vi introduserer ikke vår kristne plattform som en dimensjon i samtalen med mindre innringer selv tar opp temaet. Vi er ingen andaktstel efon, og våre medarbeidere er ikke bibelske oppsl agsverk. Som medarbeider ved Kirkens SOS må du kunne snakke med innringer om tro og tvil utfra et kristent livssyn, men du skal ikke representere kirka med synspunkter og kunnskap.

$H$ åp er et viktig aspekt i møte med den suicidale. Som medarbeider ved Kirkens SO S er du formidler av livsmot og håp - og vi opplever at mennesker som ringer oss om sine tapsopplevel ser og kriser, har et behov for à ta inn trosdimensjonen i sin samtale. Da blir håpet ett av våre viktigste temaer som et Kirkens SOS.

\section{Nye satsninger}

Kirkens SOS vil være der folk er. Som et lavterskeltilbud er det avgjørende at vi til enhver tid er tilgjengelige for den som trenger et menneske å snakke med. $M$ en hvor er folk i dag? Er tel efontjeneste det mest tilgjengelige for mennesker i dag? Dette er problemstillinger Kirkens SOS har gått aktivt inn i de siste årene, og det har resultert i flere nye satsninger. Folk er på nettet. D erfor har Kirkens SO S en pågåen de nettsatsning hvor vi har etablert en krise-e-post som kommuniserer med innskrivere i stedet for innringere. Som innskriver til vår krise-e-post kan du kommunisere med en frivillig medarbeider under felles psevdonym. Vi garanterer svar innen 24 timer. Dersom innskriver opplever sitt anliggende akutt, oppfordrer vi til å ta kontakt med Kirkens SO S via krisetelefonen - som alltid er tilgjengelig. Det har vært en omfatten de organisatorisk prosess for Kirkens SO S å gå inn i det skriftlige medium. M edarbeidere opplever det mer endelig å sen de fra seg en tekst, da en tekst kan leses og tolkes vidt forskjellig. For å imøtekomme medarbeideres engstelse for dette, samt for å ivareta kvalitetssikringen i denne tjenesten, blir enhver melding en medarbeider skriver gjennomlest og godkjent av en annen medarbeider før den returneres til innskriver. Kirkens SO S ser også at det å formidle tilstedeværelse og nærvær i tekst, er en helt annen utfordring enn per telefon (H errestad 2000). I telefonen kan vi spørre om igjen dersom vi ikke forstår, vi kan bruke vår stemme og vårt tonefall til å 


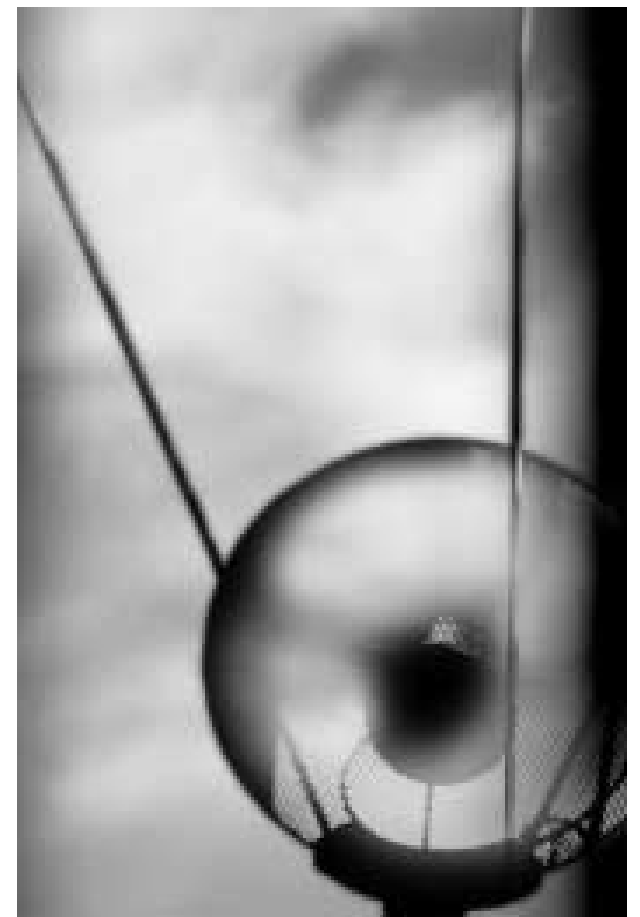

bekrefte innringer - mens vi i det skriftlige medium må klare å oppnå noe av det samme med våre ord. $M$ ange av våre innskrivere har et uttrykksbehov og et ønske om å formidle sine innerste tanker som kommer godt frem gjennom e-postmeldingen, og dette resulterer i sterke tekster. Samtidig kan vi møte korte, nakne meldinger som er like bevegende.

Følgende melding kom på krise-e-posten rett før påske: "J eg går med selvmordstanker. J eg har ingen å snakke med. K an dere hjelpe meg?" En slik mel ding krever mot og klartenkning fra medarbeider - for å klare å skape et møte som formidler livsmot og håp, slik vår målsetting er. Internasjonale erfaringer viser at kommunikasjon på nettet i stadig større grad overtar for telefontjenesten, og dette er en utfordring Kirkens SO S er rede til å ta.

Følgende sitat fra en e-postmelding kan ellers illustrere denne nye satsningen:

"Satt og sorterte mailen min... Fant en gammel mail hvor jeg fortalte dere i K irkens SO S at jeg hadde selvmordstanker og dere svarte meg. V ille bare gi dere en tilbakemelding for å si at den mailen dere sendte meg den gangen, reddet sannsynligvis livet mitt. Jeg har vært på kanten til selvmord 6 - 7 ganger, men jeg husket alltid på mailen dere sendte meg. I håp om at ting ville bli bedre. Vet du hva? I dag har jeg det så bra som jeg kan få det! Ingen selvmordstanker, ikke deprimert eller noe. Vil bare si at det nytter å hjelpe, og gi dere en tilbakemelding på at den hjelpen dere gir, faktisk redder liv. D en reddet livet mitt. D en som redder et liv, redder hele verden."

\section{Frivillighetens år 2001}

Det har gått nesten 30 år siden Kirkens SO S startet sin virksomhet i organisert form. På 70-tallet kjempet SO S for sin troverdighet - ikke fordi det var unikt med frivillig innsats, men fordi det var uvanlig å ta i bruk hverdagsmennesker i kriserelatert arbeid. I dagens landskap fremheves frivillighet som en verdi i mye sterkere grad. I dag inkluderes frivillighet i mange bedrifters virksomhetsplan, man trekker frivillige inn i helse- og omsorgssektoren, og det er en politisk vektlegging av frivillig innsats som gir frivillig sektor en sterk status. A r 2001 er FN s frivillighetsår, og dette markeres på uli ike vis rundt omkring i verden.

$\mathrm{N}$ år frivillig sektor i N orge har en større sysselsettingsverdi enn hotell- og restaurantbransjen i N orge (W ollebæk et al. 2000), og når Kirkens SO S' 1200 frivillige til sammen utgjør om lag 70 årsverk innenfor psykisk helsevern i $\mathrm{N}$ orge, da ser vi hva frivilligheten betyr. I Kirkens SOS måler vi likevel verdien av frivillig innsats i de tilbakemeldinger vi făr fra våre innskrivere og innringere. $N$ ærvær og tid, tilgjengelighet og et lyttende øre er av stor verdi i et geskjeftig og prestasjonspreget samfunn. Som medarbeider er ditt viktigste bidrag å være til stede. H er og nå er det møtet mellom medarbeider og inn ringer som er viktig og verdifullt.

I Kirkens SOS trenger ikke det vi gjør, å være verdiskapende for å være verdifullt. En innringer sa: "Jeg ringte til Kirkens SO $S$ en gang. $M$ en da det svarte, turde jeg ikke si noe. M en du verden så godt det var at det var noen der, som jeg kunneha snakket med om jeg hadde våget!"

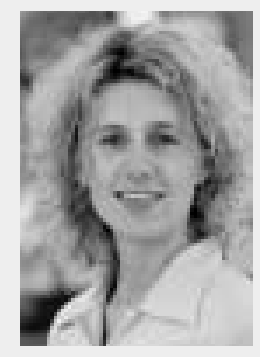

N ora B laasvær er generalsekretær i Kirkens SOS i $\mathrm{N}$ orge. Hun er cand.mag fra U niversitet i 0 slo. $\mathrm{H}$ un har organisasjonserfaring fra Kirkens SOS lokalt og nasjonalt, og yrkeserfaring fra utdanningssektoren.

\section{Kirkens SOS tilbyr samtale} med et medmenneske:

Krisetelefonen: 81533300 - døgnåpen

K rise-e-post: sos@kirkens-sos.no - svar innen 24 timer

N attåpen kirke i helgene i 0 slo og Trondheim

G rønn Linje - en krisetelefon drevet av Kirkens SOS på vegne av Forsvaret

\section{Teksttel efon for døve:}

55325697 - døgnåpen

\section{www.kirkens-sos.no}

\section{Andre telefontjenester}

$\mathbf{N}$ orges $\mathbf{R}$ øde Kors: Barn og U nges Kontakttelefon bemannes av frivillige medarbeidere. Telefonen henvender seg til barn og unge som trenger å snakke med en voksenperson. 80033321

M ental $\mathbf{H}$ else $\mathbf{N}$ orge tilbyr en hjelpetel efon for dem som er i livskrise og trenger et medmenneske å snakke med. 81003339

H uman-E tisk Forbund tilbyr støttetel efon for dem som er i en vanskelig livssituasjon. 22201133

\section{Landsforeningen for Lesbisk og} H omofil Frigjøring (LLH) bemanner en telefon som retter seg inn mot lesbiske og homofile som ønsker en samtale knyttet til sin livssituasjon. 22361948 $\mathrm{H}$ omofiles ungdomstel efon 81000277

\section{Litteratur}

G losli, Øystein. Kirkens SOS 20 år. 1994.

H errestad, H enning. Kirkens SO S' e-post-tjeneste - en bro til morgendagen. Menigheten på Internett. 0 slo: Verbum, 2000.

$\mathrm{H}$ eiberg, A strid $\mathrm{N} ø \mathrm{kl}$ eby. Frivillighet $\mathrm{i}$ endring. 2000.

Skårderud, Finn. U ro. O slo: A schehoug, 1998.

Wollebæk $D$, Selle $P$, Lorentzen $H$. Frivillig innsats, sosial integrasjon, demokrati og økonomi. K ristiansand: Fagbokforlaget, 2000. 